\title{
Controlling Near-Surface Ni Composition in Octahedral PtNi(Mo) Nanoparticles by Mo Doping for a Highly Active Oxygen Reduction Reaction Catalyst
}

\author{
F. Dionigi, ${ }^{\ddagger}$ C. Cesar Weber, ${ }^{\ddagger}$ M. Primbs, ${ }^{\ddagger}$ M. Gocyla, ${ }^{\S}$ A. Martinez Bonastre, ${ }^{\perp}$ C. Spöri, ${ }^{\ddagger}$ H. Schmies, ${ }^{\ddagger}$
} E. Hornberger, ${ }^{\ddagger}$ S. Kühl, ${ }^{\ddagger}$ J. Drnec, ${ }^{\|}$M. Heggen, ${ }^{\S}$ J. Sharman, ${ }^{\perp}$ R. Edward Dunin-Borkowski, ${ }^{\S}$ and P. Strasser $* *+\dagger$

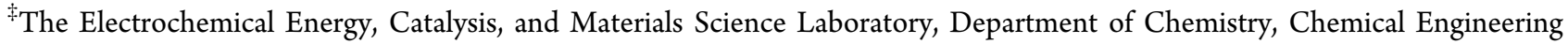
Division, Technical University Berlin, 10623 Berlin, Germany

${ }^{\S}$ Ernst Ruska-Centre for Microscopy and Spectroscopy with Electrons, Forschungszentrum Jülich GmbH, 52425 Jülich, Germany

"European Synchrotron Radiation Facility, ID 31 Beamline, BP 220, Cedex F-38043 Grenoble, France

${ }^{\perp}$ Johnson Matthey Technology Centre, Blount's Court, Sonning Common, Reading RG4 9NH, United Kingdom

${ }^{\dagger}$ Ertl Center for Electrochemistry and Catalysis, Gwangju Institute of Science and Technology, Gwangju 500-712, South Korea
\end{abstract}

Supporting Information

\begin{abstract}
We report and study the translation of exceptionally high catalytic oxygen electroreduction activities of molybdenum-doped octahedrally shaped $\mathrm{PtNi}(\mathrm{Mo})$ nanoparticles from conventional thin-film rotating disk electrode screenings $\left(3.43 \pm 0.35 \mathrm{~A} \mathrm{mg}_{\mathrm{Pt}}{ }^{-1}\right.$ at $\left.0.9 \mathrm{~V}_{\mathrm{RHE}}\right)$ to membrane electrode assembly (MEA)-based single fuel cell tests with sustained Pt mass activities of $0.45 \mathrm{~A} \mathrm{mg}_{\mathrm{Pt}}{ }^{-1}$ at $0.9 \mathrm{~V}_{\text {cell }}$, one of the highest ever reported performances for advanced shaped $\mathrm{Pt}$ alloys in real devices. Scanning transmission electron microscopy with energy dispersive X-ray analysis (STEM-EDX) reveals that Mo preferentially occupies the Pt-rich edges and vertices of the element-anisotropic octahedral PtNi particles. Furthermore, by combining in situ wide-angle X-ray spectroscopy, X-ray fluorescence, and STEM-EDX elemental mapping with electrochemical measurements, we finally succeeded to realize high $\mathrm{Ni}$ retention in

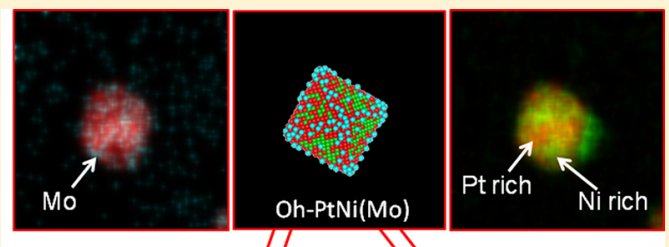
activated PtNiMo nanoparticles even after prolonged potential-cycling stability tests. Stability losses at the anodic potential limits were mainly attributed to the loss of the octahedral particle shape. Extending the anodic potential limits of the tests to the Pt oxidation region induced detectable Ni losses and structural changes. Our study shows on an atomic level how Mo adatoms on the surface impact the Ni surface composition, which, in turn, gives rise to the exceptionally high experimental catalytic ORR reactivity and calls for strategies on how to preserve this particular surface composition to arrive at performance stabilities comparable with state-of-the-art spherical dealloyed Pt core-shell catalysts.
\end{abstract}

KEYWORDS: Oxygen reduction reaction, anisotropy, surface doping, octahedral nanoparticles, PtNi alloy, membrane electrode assembly

$\mathrm{H}$ ydrogen produced by water electrolysis using electricity from renewable sources is a clean energy vector with a high gravimetric energy density. In fuel cell electric vehicles (FCEVs), proton exchange membrane fuel cells (PEMFCs) convert back the energy stored in the chemical bonds of hydrogen into electricity. While FCEVs have been recently commercialized, the sluggish kinetics of the oxygen reduction reaction (ORR) are still responsible for large overpotential losses, even in an optimized PEMFC. Among ORR catalysts, Pt emerged as one of the few elements that can withstand the harsh acidic and oxidizing conditions of ORR. However, the high price of $\mathrm{Pt}$ poses a grand challenge on the scalability of $\mathrm{Pt}$ based PEMFCs. Alloying Pt with a second metal is a successful strategy to enhance the mass activity (MA) and decrease Pt loading in vehicles. ${ }^{1}$ Several PtM alloys have been proposed with enhanced performance with respect to pure $\mathrm{Pt}^{2-8}$ among which $\mathrm{PtNi}$ and $\mathrm{PtCo}$ are probably the most investigated and among the most promising ones. In particular, shapecontrolled octahedral PtNi nanoparticles, where exposure of the (111) facet of the face-centered cubic (fcc) Pt alloy crystalline phase is maximized, have shown very high mass activity in rotating disk electrode (RDE) experiments. ${ }^{3,9-12}$

Received: May 24, 2019

Revised: August 16, 2019

Published: September 11, 2019 
Despite the promising catalytic activity evaluated in half-cell measurements, translating the performance to an actual fuel cell where the catalyst is part of a membrane electrode assembly (MEA) is known to be challenging. ${ }^{13,14}$ Only a few studies reported the performance of octahedral ${ }^{15-17}$ or more generally shaped Pt-alloy nanostructured catalysts ${ }^{18,19}$ in a PEMFC. While RDE studies constitute a practical screening method, which contributed significantly to the development of the fuel cell technology, more MEA tests in the early stage of development of a new catalyst are necessary to understand and fill this gap in performance. Besides the lack of data evaluated in MEA tests, durability is another challenge for octahedral PtNi alloy nanoparticles. In most cases, the high initial performance is not maintained during long-term stability tests due to morphological instability consisting in loss of shape and often in leaching of $\mathrm{Ni}^{3,20}$ To address this issue, ternary octahedrally shaped alloy nanoparticles, especially $\mathrm{PtNiCo}$, have been proposed. ${ }^{21-24}$ The third element is expected to finely tune the electronic and/or geometric properties of the catalysts in a synergistic manner. In case the third element, generally a metal, is present only in a low amount (i.e., $<5$ at. $\%)^{25}$ and only on the surface of the catalyst, the term "surface doping" is used. Notable examples of surface dopants for octahedral PtNi nanoparticles include $\mathrm{Rh}^{26} \mathrm{Mo},{ }^{10,27,28}$ and more recently Ga. ${ }^{16}$ Beermann et al. reported that the activity of $\mathrm{Rh}$-doped PtNi octahedra supported on carbon is improved after 4000 cycles between $0.05-1.0 \mathrm{~V}$ vs reversible hydrogen electrode (RHE) compared to a bimetallic $\mathrm{PtNi} / \mathrm{C}$ catalyst and that the shape is nearly unaffected even after 30000 cycles. $^{26}$ Lim et al. showed that both improvements in mass activity (MA) and superior stability were achieved with Ga-doped octahedral $\mathrm{PtNi} / \mathrm{C}$ compared with binary $\mathrm{PtNi} / \mathrm{C}$ and commercial $\mathrm{Pt} / \mathrm{C}^{16}$ An exceptional initial mass activity of $6.98 \mathrm{~A} \mathrm{mg}_{\mathrm{Pt}}{ }^{-1}$ at $0.9 \mathrm{~V}_{\mathrm{RHE}}$ was achieved by Huang et al. in RDE measurements by Mo-doped octahedral $\mathrm{Pt}_{3} \mathrm{Ni}$ supported on carbon. ${ }^{10}$ The electrochemical surface area (ECSA) of the catalyst was particularly high for octahedral Pt alloy nanoparticles, $67.7 \mathrm{~m}^{2} \mathrm{~g}_{\mathrm{Pt}}{ }^{-1}$ as determined from hydrogen under potential deposition $\left(\mathrm{H}_{\text {upd }}\right)$. Stability was reported to be enhanced, with only 5.5\% MA losses after 8000 potential cycles between 0.6 and $1.1 \mathrm{~V}_{\mathrm{RHE}}$ in oxygen-saturated $0.1 \mathrm{M} \mathrm{HClO}_{4}$ solution. In a recent following work, in situ X-ray absorption spectroscopy (XAS) investigation, combined with density functional theory (DFT) calculations and kinetic Monte Carlo simulations using cluster expansion, was conducted on a slightly different Mo-doped PtNi catalyst. ${ }^{28}$ The performance obtained with this new up-scaled synthesis was still considerably high, with a MA of $\sim 4 \mathrm{~A} \mathrm{mg}_{\mathrm{Pt}}{ }^{-1}$ at $0.9 \mathrm{~V}_{\mathrm{RHE}}$, an $\mathrm{H}_{\text {upd }}$-ECSA of $\sim 44 \mathrm{~m}^{2} \mathrm{~g}_{\mathrm{Pt}}{ }^{-1}$, and a MA loss of $\sim 34 \%$ after 15000 cycles in the potential range $0.6-1.0 \mathrm{~V}_{\mathrm{RHE}}$. In situ XAS of Mo k-edge proved the presence of electrochemically redoxactive Mo-oxide at the surface as predicted by DFT. The theory predicted also Mo to locate preferentially at edges and vertices of the octahedral nanoparticles. The improved activity with respect to binary $\mathrm{PtNi}$ alloys was explained by a more $\mathrm{Ni}$ rich second layer in the surface-doped catalyst, which lead to lower oxygen adsorption energies than $\mathrm{PtNi} / \mathrm{C}$ due to ligand effects. In addition, it was proposed based on theoretical calculations and in situ Pt L-edge XAS that MoOx withdraws dband electrons from nearby $\mathrm{Pt}$ atoms and stabilizes them against dissolution by about $100 \mathrm{meV}$, therefore improving the stability and stabilizing the octahedral shape. This in turn decreases dissolution of near-surface $\mathrm{Ni}$. An enhanced catalytic activity was also reported for Mo doping on other alloy systems, ${ }^{29-31}$ such as core-shell octahedral nanoparticles consisting of a Mo-doped Pt shell on the PtPd core, which were supported on ionic block copolymer-functionalized reduced graphene oxide (IG) and were tested for ORR. ${ }^{30}$ The catalytic activity enhancement was also reported for ultrathin $\mathrm{Pt}-\mathrm{Mo}-\mathrm{Ni}$ nanowires, ${ }^{31}$ which were tested for ethanol oxidation. ${ }^{31}$ In contrast, application of surface doping to large Ni-richer PtNi octahedral nanoparticles was reported to be less successful in a preliminary study, suggesting that more complicated dependencies of surface doping on other factors might exist. ${ }^{32}$ Despite the fundamental understanding of how the surface doping increases the performance of octahedral PtNi alloy nanoparticles is improved by employing more advance calculations ${ }^{27,28}$ and in situ XAS, ${ }^{28}$ some open questions still remain. These include, especially, lack of experimental evidence for the location of Mo atoms and dependence of surface doping on surface elemental composition and on nanoparticle growth mechanism. Furthermore, the role and extent of surface doping in improving the stability is not perfectly clear.

In this study, we addressed these questions by combining in situ wide-angle X-ray scattering (WAXS) performed with highenergy synchrotron radiation with scanning transmission electron microscopy-energy dispersive X-ray analysis (STEM-EDX) elemental mapping, X-ray fluorescence (XRF) spectroscopy, and electrochemical characterization by RDE. We have found that Mo dopants preferentially locate on Ptrich edges and vertices of octahedral $\mathrm{PtNi}$ nanoparticles, confirming the theoretical predictions. ${ }^{10,27,28}$ We show that on elemental anisotropic PtNi octahedral nanoparticles Mo surface doping enhances the MA with respect to binary $\mathrm{PtNi} / \mathrm{C}$. This result expands what has been predicted by theory, where calculations were performed on alloys with either an ordered crystalline phase ${ }^{27}$ or with random initial atomic arrangement. ${ }^{28}$ Regarding the catalyst durability, we show that a high content of $\mathrm{Ni}$ is preserved in $\mathrm{Mo}-\mathrm{PtNi} / \mathrm{C}$ during stability tests and the stability is slightly better than for binary $\mathrm{PtNi} / \mathrm{C}$. However, morphological changes in shape still occur during potential cycling, leading to concave octahedral and smaller shape-undefined nanoparticles. Negligible structural changes were observed in the crystalline domains analysis during the 5000 cycles stability protocol with upper potential limitation (life operation regime), while a start-up/shut-down protocol severely led to an expansion of lattice distances corresponding to $\mathrm{Ni}$ leaving the $\mathrm{PtNi}$ alloy phase domains. Finally we confirm the high promises for fuel cell application of the oh- $\mathrm{PtNi}(\mathrm{Mo}) / \mathrm{C}$ catalyst by translating its performance in membrane electrode assembly (MEA)-based single fuel cell tests $\left(0.45 \mathrm{~A} \mathrm{mg}_{\mathrm{Pt}}^{-1}\right.$ at $\left.0.9 \mathrm{~V}_{\text {cell }}\right)$ from the one measured in thin-film $\mathrm{RDE}$ screening tests $\left(3.43 \pm 0.35 \mathrm{~A} \mathrm{mg}_{\mathrm{Pt}}{ }^{-1}\right.$ at 0.9 $\left.\mathrm{V}_{\mathrm{RHE}}\right)$. In conclusion, our results suggest that a combination of surface doping with control of elemental composition of the (111) facets is necessary to further extend the stability of this class of catalysts. Our study is relevant for the design of ORR active and stable $\mathrm{Pt}$ alloy nanoparticles at the atomic- and nanoscale.

PtNi and Mo-doped PtNi nanoparticles, in the following $\mathrm{PtNi}(\mathrm{Mo})$, have been synthesized following a solvothermal method, which has been adapted and upscaled from previously reported work ${ }^{10}$ in order to achieve amounts of catalyst that were enough to perform extended characterization on the same batch. The synthesis consisted of two steps (Figure 1a). 

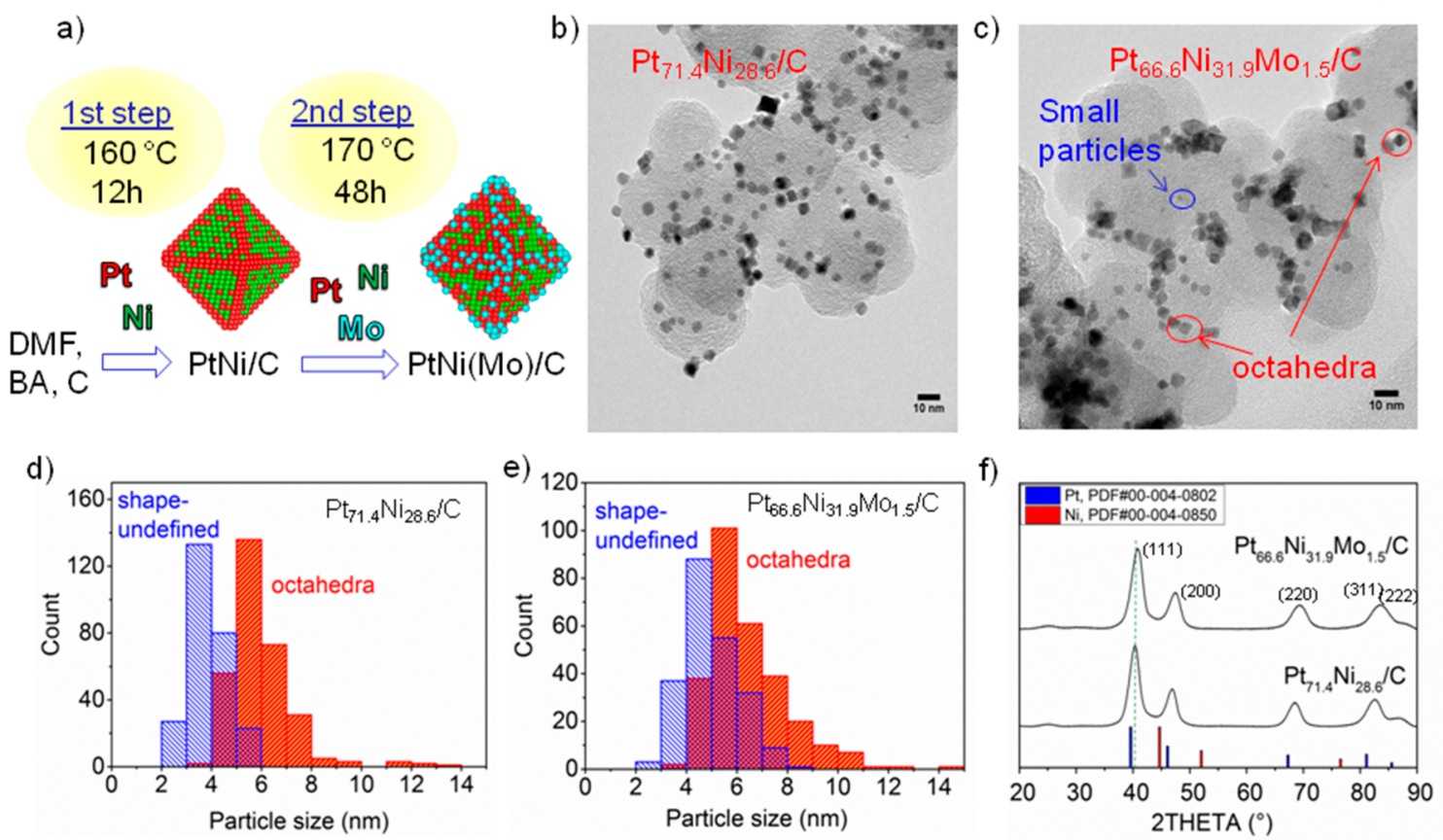

Figure 1. Schematic illustration (a) describing the two-step synthesis of $\mathrm{PtNi}(\mathrm{Mo})$ octahedra through the intermediate synthesis of PtNi octahedra. $\mathrm{Pt}$ atoms are shown in red, $\mathrm{Ni}$ atoms in green, and $\mathrm{Mo}$ in cyan. TEM images of $\mathrm{PtNi} / \mathrm{C}(\mathrm{b})$ and $\mathrm{PtNi}(\mathrm{Mo}) / \mathrm{C}(\mathrm{c})$. The composition obtained by ICP-OES is indicated. Nanoparticle size distributions obtained by TEM analysis for PtNi/C (d) and PtNi(Mo)/C (e). XRD patterns (f) for both $\mathrm{PtNi}(\mathrm{Mo})$ (top) and PtNi (bottom). The peaks were indexed based on fcc structure, and the patterns for Pt (blue bars, PDF no. 00-004-0802) and $\mathrm{Ni}$ (red bars, PDF no. 00-004-0850) are also shown. The vertical dashed green line is a guide to the eyes to highlight the small shift.

In the first step, octahedral $\mathrm{PtNi}$ on carbon support are synthesized in a glass lined autoclave heated at $160{ }^{\circ} \mathrm{C}$ for $12 \mathrm{~h}$. This is achieved by addition and sonication of $\mathrm{Pt}$ and $\mathrm{Ni}$ acetyl-acetonate precursors $\left(\mathrm{Pt}(\mathrm{acac})_{2}\right.$ and $\left.\mathrm{Ni}(\mathrm{acac})_{2}\right)$ and benzoic acid (BA) in an anhydrous $N, N$-dimethylformamide (DMF) suspension of carbon Vulcan nanoparticles (Cabot XC $72 \mathrm{R})$. In the second step, the surface doping and further growing are achieved by adding extra $\mathrm{Pt}$ and $\mathrm{Ni}$ precursors as well as Mo hexacarbonyl $\left(\mathrm{Mo}(\mathrm{CO})_{6}\right)$ to the suspension from step 1. The suspension is then heated in the autoclave at 170 ${ }^{\circ} \mathrm{C}$ for $48 \mathrm{~h}$. Nanoparticles were collected after step 1 or step 2; in both cases, the autoclave was left to cool down naturally, and the suspension (Figure S1) was washed several times and freeze-dried overnight. All details of the synthesis and experimental methods are provided in the Supporting Information. The elemental composition as well as the Ptbased weight loading on the carbon support was determined by inductively coupled plasma optical emission spectroscopy (ICP-OES). The compositions of the as-prepared catalysts were $\mathrm{Pt}_{71.4} \mathrm{Ni}_{28.6}$ and $\mathrm{Pt}_{66.6} \mathrm{Ni}_{31.9} \mathrm{Mo}_{1.5}$. The Pt-based weight loadings were $21.5 \mathrm{Pt}$ wt $\%$ and $17.9 \mathrm{Pt}$ wt $\%$, respectively. The $\mathrm{Pt} / \mathrm{Ni}$ ratio and the Mo composition are similar, but slightly $\mathrm{Ni}$-richer, than the previously reported highly active Mo-doped catalysts $\left(\mathrm{Pt}_{73.4} \mathrm{Ni}_{25.0} \mathrm{Mo}_{1.6} / \mathrm{C}^{10}\right.$ and $\left.\mathrm{Pt}_{70.0} \mathrm{Ni}_{28.6} \mathrm{Mo}_{1.4} / \mathrm{C}^{28}\right)$. The Pt-based weight loading of $\sim 20 \mathrm{Pt}$ wt $\%$ was targeted after an optimization that we performed in a preliminary screening study. TEM images of the as-prepared $\mathrm{PtNi} / \mathrm{C}$ and $\mathrm{PtNi}(\mathrm{Mo}) /$ $\mathrm{C}$ catalysts are shown in Figure 1b,c. The images show successful preparation of size-reduced sub-10 nm octahedra. Overall, the catalysts are composed of a mixture of small shapeundefined and octahedral nanoparticles, which in some area form agglomerates. The nanoparticle size distribution is reported as histograms in Figure 1d,e and the average value in Table 1. A slightly higher particle size, although within the error, is obtained for $\mathrm{PtNi}(\mathrm{Mo})$ probably due to the addition of extra precursors and the longer reaction time.

Table 1. Nanoparticle Size Distribution Obtained from TEM Analysis

\begin{tabular}{lcc} 
& \multicolumn{2}{c}{ average particle size $(\mathrm{nm})$} \\
\cline { 2 - 3 } & $\mathrm{PtNi} / \mathrm{C}$ & $\mathrm{PtNi}(\mathrm{Mo}) / \mathrm{C}$ \\
all nanoparticles & $5.0 \pm 1.5$ & $5.8 \pm 1.5$ \\
shape-undefined & $3.9 \pm 0.7$ & $5.0 \pm 1.0$ \\
octahedra & $6.0 \pm 1.3$ & $6.4 \pm 1.6$ \\
\hline
\end{tabular}

Powder X-ray diffraction (XRD) patterns of the as-prepared samples (Figure 1f) are consistent with the fcc phase structure with reflections at intermediate $2 \theta$ angles between the pure $\mathrm{Pt}$ and $\mathrm{Ni}$, revealing the formation of $\mathrm{PtNi}$ alloy domains. The small shift toward higher $2 \theta$ angles for $\mathrm{PtNi}(\mathrm{Mo})$ with respect to $\mathrm{PtNi}$ is consistent with the slightly higher $\mathrm{Ni}$ content of the surface-doped catalyst. High-angle annular dark-field (HAADF) STEM and STEM-EDX elemental mapping was performed on selected single octahedral nanoparticles from asprepared $\mathrm{PtNi} / \mathrm{C}$ and $\mathrm{PtNi}(\mathrm{Mo}) / \mathrm{C}$. For both $\mathrm{PtNi} / \mathrm{C}$ (Figure $\mathrm{S} 2$ ) and $\mathrm{PtNi}(\mathrm{Mo}) / \mathrm{C}$ (Figure 2; Figures $\mathrm{S} 3$ and $\mathrm{S} 4$ ), the STEM-EDX elemental mapping shows that the octahedra display an anisotropic element distribution with Pt-rich edges and vertices and Ni-rich facets. A similar element distribution was reported by our group for larger $\mathrm{PtNi}^{20}$ and $\mathrm{PtNiCo}^{21}$ nanoparticles synthesized by a similar method but in the absence of benzoic acid and at lower temperatures. Mo was as well detected (Figure 2; Figures S3d and S4), and the STEMEDX combined map of $\mathrm{Pt}$ and Mo highlights its presence at the surface of the octahedral nanoparticles, as predicted by the theory and proposed in a previous XAS work. ${ }^{10,27,28}$ 

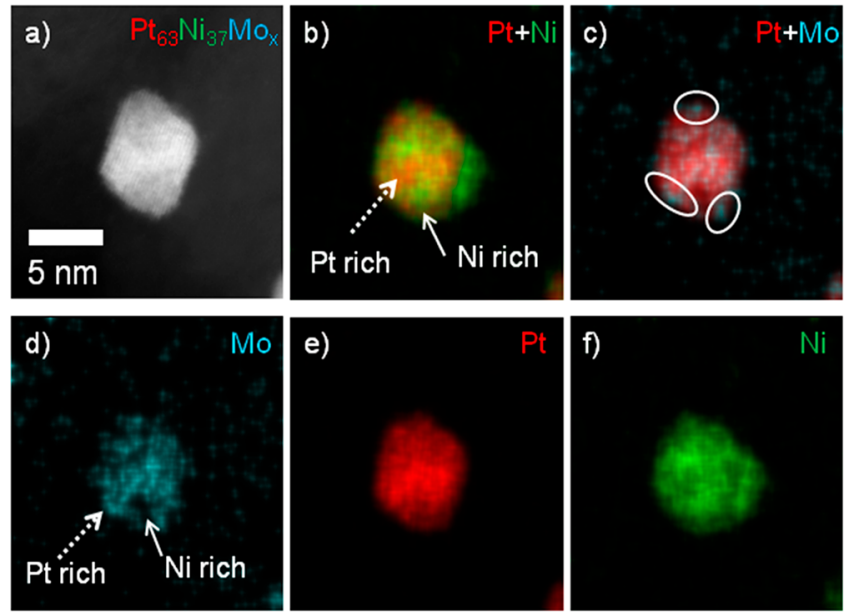

Figure 2. HAADF-STEM image (a) and STEM-EDX composition maps (b-f) of a $\mathrm{PtNi}(\mathrm{Mo})$ octahedral nanoparticle from an asprepared sample. Pt (red) and $\mathrm{Ni}$ (green) combination (b), Pt and Mo (cyan) combination (c), and singular Mo (d), Pt (e), and Ni (f) maps are shown. The nanoparticle composition determined by EDX is inserted in panel a. Pt-rich and Ni-rich areas are indicated by arrows, while circles highlight Mo enrichment at the edge of the nanoparticle.

Furthermore, the comparison of the combined $\mathrm{Pt}-\mathrm{Ni}$ elemental map with the Mo elemental map reveals that Mo is preferentially located at the Pt-rich edges and vertices, while its presence on Ni-rich areas is limited (see Figure $2 \mathrm{~d}$ and Figure S4d). The Mo decoration of vertices and edges is in agreement with theoretical predictions, ${ }^{10,27,28}$ even though the predictions were performed on non-anisotropy element distributed octahedra. They also indicate that a dependency of the Mo surface doping and especially of the Mo location might exist in relation to the $\mathrm{PtNi}$ octahedral surface composition. This is a possible explanation of the lack of activity enhancement observed with previously anisotropic element distributed Ni-rich PtNi octahedra, which are typically characterized by extended Ni-rich (111) PtNi facets. ${ }^{32}$

Besides the preferential Mo enrichment on edges and vertices, we find that a minor Mo amount is also present on the facets. The Mo composition is about 1 at. \% and therefore close to the error of measurement of the STEM-EDX analysis. In addition, a precise deconvolution of the overlapping Mo-L peak and Pt-M side peaks is difficult and hence a determination of the Mo composition is prone to errors. The Mo map is influenced by this overlap as well and might show a mixture between the actual Mo and residual Pt. Due to this effect and the small amount of Mo detected, we only indicate the Ni and Pt composition for single nanoparticles. Nonetheless Figure 2c and the comparison between Figure 2 d,e show that there are areas that are richer in Mo than a bare overlapping $\mathrm{Pt}$ contribution would suggest. These areas are mostly at the corners of the octahedron, confirming the hypothesis related to the preferential location of Mo at low-coordinated Pt sites.

It was found that smaller octahedral nanoparticles like the one in Figure 2, $\sim 7.5 \mathrm{~nm}$ along the axis, have a Pt-richer composition, Pt:Ni $=63: 37$, than larger octahedral nanoparticles, like the one in Figure S4, $\sim 9.5 \mathrm{~nm}$ and $\mathrm{Pt}: \mathrm{Ni}=48: 52$. This size-composition correlation is consistent with a growth study on anisotropic element distributed PtNi octahedra ${ }^{20}$ and, in our case, can be ascribed to local variation in the availability of metal precursors. Some of the small pseudospherical nanoparticles observed in the TEM overview (Figure 1c) are also shown in the STEM-EDX composition map of Figure S4. Their size was $\sim 3.5 \mathrm{~nm}$, and they were found to be particularly Pt-rich, which is consistent with our growth model, and interestingly also decorated with Mo. In a preliminary screening study, we have found that the amount of Mo surface doping is self-limiting and never achieves values higher than 3 at. \%, while values between 0.9 and 1.8 at. \% were typically achieved. We propose that this is due to the Pt catalyzed reduction of Mo being dependent on the available Pt ECSA, even though more experiments exploring a wide range of $\mathrm{Pt}$ ECSA are necessary to prove this hypothesis.

To understand the role of Mo and to determine the ORR activity and stability, we performed a series of experiments using thin-film $\mathrm{RDE}$ in acidic media $\left(0.1 \mathrm{M} \mathrm{HClO}_{4}\right)$ following an established protocol. ${ }^{33}$

Due to the low at. \% amount of Mo, it was difficult to investigate systematically the activity trend dependence on the Mo content; therefore, in the following, the best performing octahedral Mo-doped $\mathrm{PtNi} / \mathrm{C}$ nanoparticle catalyst (oh$\mathrm{PtNi}(\mathrm{Mo}) / \mathrm{C}$ ) is compared with binary octahedral $\mathrm{PtNi}$ nanoparticles obtained after the first step (oh-PtNi/C) and two commercial catalysts: a Pt/C and a dealloyed PtNi/C (d$\mathrm{PtNi} / \mathrm{C}$ ). Figure 3 a shows the cyclic voltammograms recorded at $20 \mathrm{mVs}^{-1}$ of $\mathrm{PtNi}(\mathrm{Mo}) / \mathrm{C}$ after activation (50 cycles, $0.05-$ $0.925 \mathrm{~V}_{\mathrm{RHE}}, 100 \mathrm{mVs}^{-1}, \mathrm{~N}_{2}$ saturated electrolyte) and after the stability test protocol (10000 cycles, 0.6-0.925 $\mathrm{V}_{\mathrm{RHE}}, 100$ $\mathrm{mVs}^{-1}, \mathrm{~N}_{2}$ saturated electrolyte).

After the stability test, some peaks emerged at low potentials, at which $\mathrm{H}_{\text {upd }}$ and oxidation occurs, indicating local changes on the surface and faceting, i.e., increase in the (110) contribution. ${ }^{34}$ The CV and $\mathrm{LSV}$ of $\mathrm{PtNi} / \mathrm{C}$ are shown in Figure S5 and display a similar qualitative behavior. However, a difference in the CV is notable: in the case of $\mathrm{PtNi}(\mathrm{Mo})$ two weak peaks are present between 0.35 and 0.55 $\mathrm{V}_{\mathrm{RHE}}$ and become more visible at a higher loading (Figure S6), which are not present in the $\mathrm{PtNi} / \mathrm{C}$. These peaks are hardly affected by the stability test. Since, according to the Pourbaix diagram of $\mathrm{Mo},{ }^{35}$ a redox transition between $\mathrm{MoO}_{2}$ and $\mathrm{MoO}_{3}$ and involving intermediate phases is expected at those potentials, we tentatively attributed these peaks to redox of Mo. A similar redox couple at ca. $0.45 \mathrm{~V}$ vs RHE was also reported by Elezovic et al. and attributed to Mo oxidation for $\mathrm{Pt} / \mathrm{C}$-doped by MoOx. ${ }^{36}$ It is worth noticing that during the fast potential scans of $\mathrm{CV}$ the full reduction to $\mathrm{MoO}_{2}$ might not occur, while a proton intercalation with concomitant reduction of $\mathrm{Mo}(\mathrm{VI})$ to $\mathrm{Mo}(\mathrm{V})$ following the equation: $x \mathrm{H}^{+}+$ $x \mathrm{e}^{-}+\mathrm{MoO}_{3} \leftrightarrow \mathrm{H}_{x} \mathrm{MoO}_{3}$ might be more likely according to the literature. ${ }^{37}$ This observation is in agreement with Mo being present at the surface in an oxidized state and electrochemically redox active. ${ }^{28}$ More experiments are necessary to show, for example, correlation between the peak heights and Mo amount. In addition to the analysis of the $\mathrm{H}_{\text {upd }}$ potential range, electrochemical characterization by $\mathrm{CO}$ stripping of the catalysts was performed and it is discussed in Supporting Information (see discussion and Figures S7S11).

For electrochemical ORR activity measurements, linear sweep voltammetry (LSV) was performed and the curves for the activated state and the state after stability test are shown in Figure $3 \mathrm{~b}$ and Figure $\mathrm{S} 5 \mathrm{~b}$ for $\mathrm{PtNi}(\mathrm{Mo}) / \mathrm{C}$ and $\mathrm{PtNi} / \mathrm{C}$, respectively. The $\mathrm{H}_{\text {upd }}$-ECSA values for octahedral $\mathrm{PtNi} / \mathrm{C}$ and $\mathrm{PtNi}(\mathrm{Mo}) / \mathrm{C}$ are similar, $\sim 38 \mathrm{~m}^{2} \mathrm{~g}_{\mathrm{Pt}}{ }^{-1}$, and lower than the 

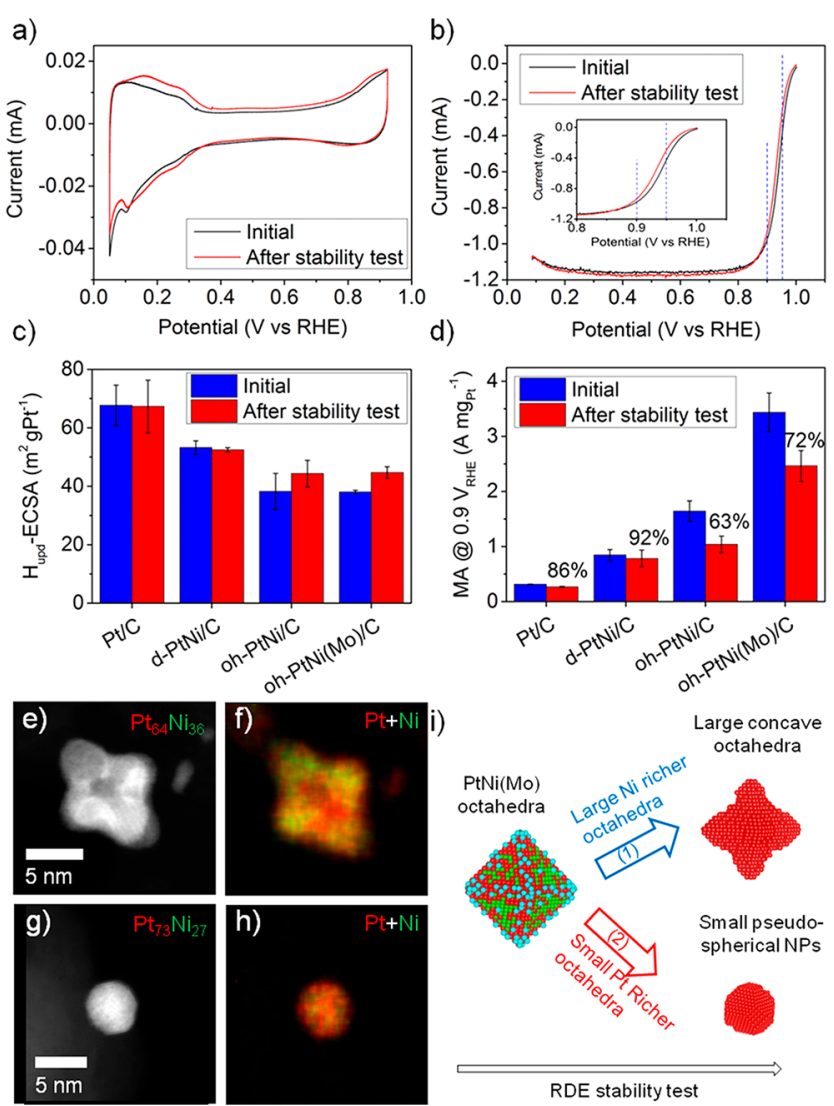

Figure 3. Electrochemical characterization, ORR activity, and stability of oh-PtNi(Mo)/C. Cyclic voltammetry (a) and linear sweep voltammetry (b) after activation (black) and after the stability test (red) for oh-PtNi(Mo)/C. The insert in panel b shows a magnification for potentials more anodic than the purely diffusion limited regime, while vertical dashed lines indicate potentials of 0.9 $\mathrm{V}_{\mathrm{RHE}}$ and $0.95 \mathrm{~V}_{\mathrm{RHE}}$, at which the ORR mass activity is reported. Both $\mathrm{CV}$ and LSV were obtained at $20 \mathrm{mVs}^{-1}$ and $0.1 \mathrm{M} \mathrm{HClO}_{4}$ electrolyte. In panel a, the electrolyte was saturated with $\mathrm{N}_{2}$ and with a rotation equal to $0 \mathrm{rpm}$, while in panel $\mathrm{b}$ saturation with $\mathrm{O}_{2}$ and $1600 \mathrm{rpm}$ was used. (c) $\mathrm{H}_{\mathrm{upd}}$-ECSA after activation (blue) and after stability test (red) for $\mathrm{Pt} / \mathrm{C}$, d-PtNi/C, oh-PtNi/C, oh-PtNi(Mo)/C. (d) Mass activity at $0.9 \mathrm{~V}_{\mathrm{RHE}}$ for the same catalysts. In both panels $\mathrm{C}$ and $\mathrm{d}$, the error bars represent standard error from the average of at least three measurements obtained using three different electrodes and inks. HAADF STEM image (e,g) and STEM-EDX composition maps $(\mathrm{f}-\mathrm{h})$ of $\mathrm{PtNi}(\mathrm{Mo}) / \mathrm{C}$ after a stability protocol conducted using $\mathrm{RDE}$. A concave octahedron is shown in panels $e$ and $f$ while a pseudospherical particle is shown in panels $\mathrm{g}$ and $\mathrm{h}$. For the combined elemental map, $\mathrm{Pt}$ is shown in red and $\mathrm{Ni}$ in green. One nanoparticle composition as determined by EDX is inserted in panels e and g. In panel i, a schematic illustration of the two proposed degradation pathways is shown. $\mathrm{Pt}$ atoms are shown in red, Ni atoms in green, and Mo in cyan.

reference commercial catalysts (Figure 3c). This value is comparable and only slightly smaller than what was obtained by Jia et al. for a similar Mo-doped $\mathrm{PtNi} / \mathrm{C}$ catalyst, ${ }^{28}$ while much smaller than $67.7 \mathrm{~m}^{2} \mathrm{~g}_{\mathrm{Pt}}{ }^{-1}$ reported by Huang et al., ${ }^{10}$ which is likely due to different synthesis conditions. After the stability test, while the commercial catalysts negligible changes in the $\mathrm{H}_{\text {upd }}$-ECSA are observed, the ECSA of the octahedral catalysts slightly increases. This is in agreement with faceting and roughening of the surface, as evidenced from inspection of the profile of the CV curves.
The initial ORR mass activity of the catalysts evaluated at $0.9 \mathrm{~V}_{\mathrm{RHE}}$ increases in the following order: $\mathrm{Pt} / \mathrm{C}, \mathrm{d}-\mathrm{PtNi} / \mathrm{C}$, oh$\mathrm{PtNi} / \mathrm{C}$, oh-PtNi(Mo)/C (Figure 3d). In particular, the oh$\mathrm{PtNi}(\mathrm{Mo}) / \mathrm{C}$ shows a very high mass activity, $3.43 \pm 0.35 \mathrm{~A}$ $\mathrm{mg}_{\mathrm{Pt}}{ }^{-1}$, a value that is double the one from oh-PtNi/C (1.64 \pm $\left.0.19 \mathrm{~A} \mathrm{mg}_{\mathrm{Pt}}{ }^{-1}\right)$, and an order of magnitude higher than the one of commercial $\mathrm{Pt} / \mathrm{C}$. This value is comparable with the one reported by Jia et al., $\sim 4 \mathrm{~A} \mathrm{mg}_{\mathrm{Pt}}{ }^{-1}$, ${ }^{28}$ that was obtained with the same scan rate used in our work, $20 \mathrm{mVs}^{-1}$, for another Mo-doped $\mathrm{PtNi} / \mathrm{C}$ catalyst. Both values are smaller than the highest MA reported for a Mo-doped $\mathrm{PtNi} / \mathrm{C}$ catalyst $(6.98 \mathrm{~A}$ $\mathrm{mg}_{\mathrm{Pt}}{ }^{-1}$, measured at $\left.10 \mathrm{mVs}^{-1}\right) .{ }^{10}$ However, the differences in specific activity (SA) among the three catalysts discussed above are smaller due to the lower ECSA of the two less active catalysts. This could suggest that the type of active site in the three Mo-doped catalysts is similar, and the difference among them is the result of different Pt utilization. This can be related to nanoparticle agglomerations possibly depending on the amount of catalysts synthesized in the three cases or in general to other synthesis procedure differences.

As shown in Figure $3 \mathrm{~b}$, the current at $0.9 \mathrm{~V}_{\mathrm{RHE}}$ is close to the diffusion limiting current; however, it was not possible to further decrease the $\mathrm{Pt}$ loading on the electrode while obtaining a homogeneous film. Therefore, we report also the mass activity evaluated at $0.95 \mathrm{~V}_{\mathrm{RHE}}$, as a common practice for recent high activity catalysts: ${ }^{10,38} 0.36 \pm 0.06 \mathrm{~A} \mathrm{mg}_{\mathrm{Pt}}{ }^{-1}$. Compared with the most active catalysts in the literature, the $\mathrm{MA}$ at $0.95 \mathrm{~V}_{\mathrm{RHE}}$ is smaller than the one for the highly active $\mathrm{Pt}_{3} \mathrm{Ni} / \mathrm{C}$ nanoframes $\left(0.97 \mathrm{~A} \mathrm{mg}_{\mathrm{Pt}}{ }^{-1}\right)^{38}$ and previously reported octahedral $\mathrm{PtNi}(\mathrm{Mo}) / \mathrm{C}\left(1.41 \mathrm{~A} \mathrm{mg}_{\mathrm{Pt}}{ }^{-1}\right),{ }^{10}$ which have also a higher $\mathrm{MA}$ at $0.9 \mathrm{~V}_{\mathrm{RHE}}$. Nonetheless, the reported $\mathrm{MA}$ at $0.95 \mathrm{~V}_{\mathrm{RHE}}$ is not reached by $\mathrm{Pt} / \mathrm{C}$ neither at $0.9 \mathrm{~V}_{\mathrm{RHE}}$, confirming the high ORR activity of the catalyst. Due to the slight difference in $\mathrm{Ni}$ content between $\mathrm{PtNi}$ and $\mathrm{PtNi}(\mathrm{Mo})$, we further investigate if the activity enhancement was due to the $\mathrm{Ni}$ enrichment and the role of Mo surface doping in relation to this enrichment. Therefore, we synthesized a variation of $\mathrm{PtNi}$ following the two-step synthesis used for $\mathrm{PtNi}(\mathrm{Mo})$, but adding only $\mathrm{Pt}$ and Ni precursors in the second step and so omitting the Mo precursor (oh-PtNi/C-2steps). The Pt-based weight loading, 18.9 Pt wt \%, was comparable with the other catalysts. The $\mathrm{Pt}$ and $\mathrm{Ni}$ composition was $\mathrm{Pt}_{68.6} \mathrm{Ni}_{31.4}$, very similar to the one of $\mathrm{PtNi}(\mathrm{Mo})$, further confirming that the higher $\mathrm{Ni}$ content of $\mathrm{PtNi}(\mathrm{Mo})$ with respect to the one-step $\mathrm{PtNi}$ does not require the presence of a Mo precursor but was due to other characteristics of the additional second step, i.e., extra Ni precursors and/or a longer time. Besides the fact that $\mathrm{Ni}$ composition was similar to $\mathrm{PtNi}(\mathrm{Mo})$, the ORR activity was comparable to the one-step $\mathrm{PtNi}, 1.93 \pm 0.49 \mathrm{~A} \mathrm{mg}_{\mathrm{Pt}}{ }^{-1}$. This shows that the Mo surface doping is involved in the activity enhancement. Despite the bulk $\mathrm{Ni}$ content of the as-prepared catalysts seemed not related to the activity enhancement of the element-anisotropic $\mathrm{PtNi}(\mathrm{Mo}) / \mathrm{C}$, a different argument might hold for subsurface $\mathrm{Ni}$ or $\mathrm{Ni}$ content of the activated catalysts. For example, in a recent paper $^{28}$ from a series of studies, ${ }^{10,27,28}$ Müller and coworkers have proposed that the enhancement in activity is due to the enrichment of subsurface $\mathrm{Ni}$ after activation in connection to the stabilization of surface $\mathrm{Pt}$ atoms caused by Mo surface doping.

For simplicity in the following, we will discuss the stability of oh- $\mathrm{PtNi}(\mathrm{Mo}) / \mathrm{C}$ in comparison with only the one-step oh$\mathrm{PtNi} / \mathrm{C}$ and the two commercial catalysts. After the stability 


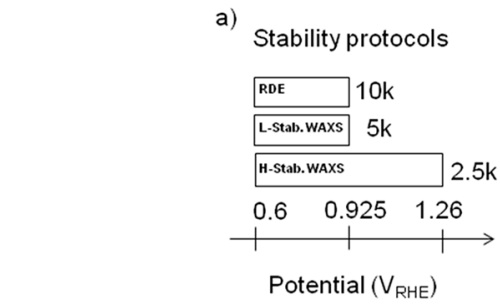

b) -Activated- After L-Stability-After H-Stability

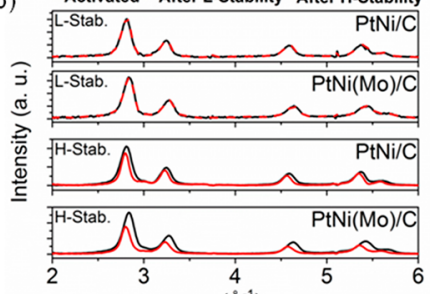

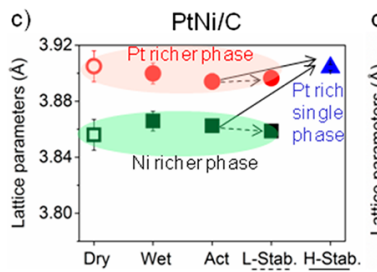
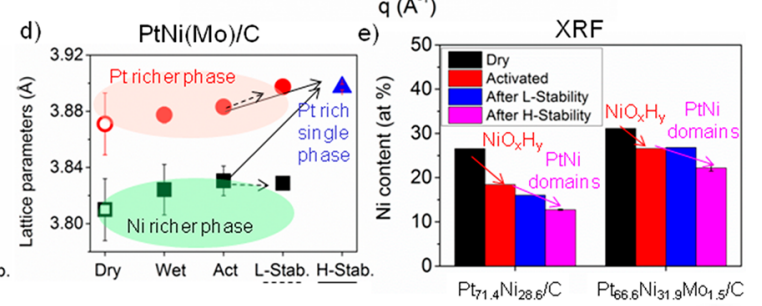

Figure 4. Stability study by combined in situ WAXS and XRF. (a) Schematic illustration of the stability test protocol used in RDE experiments and the two used in in situ WAXS. (b) Background subtracted patterns obtained with in situ WAXS for the activated state (black) and after L-stability (red dashed) and H-stability (red solid) protocols for $\mathrm{PtNi} / \mathrm{C}$ and $\mathrm{PtNi}(\mathrm{Mo}) / \mathrm{C}$. Comparison of the lattice parameter calculated with Rietveld refinement for dry, wet, activated, L-stability, and $\mathrm{H}$-stability for $\mathrm{PtNi} / \mathrm{C}$ (c) and $\mathrm{PtNi}(\mathrm{Mo}) / \mathrm{C}$ (d). For the first four states, a two-phase composition shows the best fit, and the two phases are indicated as a Pt-rich (red dots) and a Ni-rich (black squares) phase. Open symbols are used for measurements obtained by laboratory XRD, while full symbols represent synchrotron measurements. Pink and green ovals highlight the similarity of the phases among the three states. For $\mathrm{H}$-stability, a single phase was used in the fit (blue triangles). Dashed and solid black arrows are guides to the eye to show that stability tests follow activation. Error bars represent standard deviations provided by Topas for the refined parameters. (e) Ni at. \% composition from XRF measurements of samples in the dry state (black), activated (red), after L-stability (blue), and Hstability (pink). The metal composition refers to only Pt and Ni metals, since Mo was beyond the XRF detection limit for all samples. The error bars for the $\mathrm{H}$-stability data represent the standard deviation from the average between different samples. Arrows represent the proposed two main mechanisms of Ni leaching: from XRD amorphous surface $\mathrm{NiO}_{x} \mathrm{H}_{y}$ (red) and fcc PtNi alloy domains (pink).

test, the MA losses are $28 \%$ and $37 \%$ for oh-PtNi(Mo)/C and oh-PtNi/C, respectively. Therefore, the durability appears slightly improved for oh- $\mathrm{PtNi}(\mathrm{Mo}) / \mathrm{C}$ with respect to the binary oh-PtNi/C. However, the losses of the octahedral catalysts are still much larger compared to the ones of commercial $\mathrm{Pt} / \mathrm{C}$ and $\mathrm{d}-\mathrm{PtNi} / \mathrm{C}$. For practical application, it would be highly important to further improve the stability. This requires a detailed investigation of the degradation mechanism. For oh-PtNi/C, TEM investigations performed after the stability tests revealed a general loss of octahedrally shaped nanoparticles (Figure S12), which is in agreement with the fact that the activity after stability is almost approaching the initial activity of $\mathrm{d}-\mathrm{PtNi} / \mathrm{C}$. On the other hand, despite the $28 \%$ MA loss, the activity of oh- $\mathrm{PtNi}(\mathrm{Mo}) / \mathrm{C}$ is still very high after stability tests. HAADF-STEM imaging and STEM-EDX elemental mapping were performed after the stability test of oh- $\mathrm{PtNi}(\mathrm{Mo}) / \mathrm{C}$ to investigate its morphological stability (Figure 3e-h; Figures S13 and S14).

It was found that the sample consisted of a mixture of small pseudospherical nanoparticles and larger concave octahedra. This morphological change is in agreement with changes in the $\mathrm{CV}$. Two examples are shown in Figure $3 \mathrm{e}-\mathrm{h}$ and Figure S14, a $9 \mathrm{~nm}$ concave $\mathrm{Pt}_{64} \mathrm{Ni}_{36}$ octahedron and a $5 \mathrm{~nm}$ pseudospherical $\mathrm{Pt}_{73} \mathrm{Ni}_{27}$ nanoparticle. Mo was below the detection limit, implying a possible partial or complete loss of Mo during the stability test. Interestingly, for the concave octahedral nanoparticle in Figure 3e,f, a Pt shell is present as well as a Pt-richer core and the $\mathrm{Ni}$ content is quite high, comparable to that of the $7.5 \mathrm{~nm}$ octahedral nanoparticle found in the as-prepared sample. This high retained Ni content might be responsible for the fact that, despite the losses, the MA after the stability test is still considerably high.

We propose a dual degradation mechanism for the PtNi(Mo) octahedral (Figure 3i): (1) large Ni-richer octahedra, which possess extended Ni-rich PtNi facets due to the anisotropic element distribution, experience corrosion of the facets until a stable Pt shell is formed, resulting in concave octahedra, which is in agreement with previous work on similar nanoparticles; ${ }^{3}$ (2) in smaller and average-sized octahedra, which are Pt-richer and have smaller facets, the corrosion of facets competes with the corrosion of highly reactive $\mathrm{Pt}$ at the edges and vertices resulting in the pseudospherical shape, as reported for other Pt-rich octahedral PtNi nanoparticles. ${ }^{26}$

Understanding atomic scale structural changes connected to $\mathrm{Ni}$ leaching is fundamental to gain insights in the MA loss, being the activity of this class of catalysts strongly dependent on the (geometric) lattice strain induced by the alloying process. $^{39}$ A combined WAXS and XRF study (Figure 4; Figures S15-S19) was conducted to further investigate the structural implication of $\mathrm{Ni}$ retention with the evolution of the activity during cycling.

For the in situ WAXS experiments, oh-PtNi/C and oh$\mathrm{PtNi}(\mathrm{Mo}) / \mathrm{C}$ catalysts were drop casted from presonicated inks on a carbon paper stripe, which was previously cut from a gas diffusion layer (GDL) sheet (SIGRACET, SGL group) (Figure S15a). The amount of catalyst deposited, $\sim 9.8 \mu \mathrm{g}_{\mathrm{Pt}}$ is five times the one used for thin-film RDE experiments. A homemade PEEK cell (Figure S15b), which had two openings covered by PEEK foil as X-ray windows, was used and filled with $0.1 \mathrm{M} \mathrm{HClO}_{4}$. During operation, the electrolyte was in equilibrium with air. The samples were measured after inserting the electrolyte (wet state), after activation by the same protocol used in RDE experiments (activated state) and during and after the stability test. Two stability protocols were investigated and schematically illustrated in Figure 4a. Both stability tests were performed after a fresh sample was activated. One protocol (L-stability, where "L" stands for low upper potential) was designed to simulate lifetime operation, 
where exposure to high anodic potentials is prevented, and was simply the stability protocol used in RDE experiments ${ }^{33}$ but with half the number of cycles. The other protocol (H-stability, where " $\mathrm{H}$ " stands for high upper potential) was designed to consider the effect of start-up/shut-down, where high anodic potentials can be reached. The upper potential was increased to $1.26 \mathrm{~V}_{\mathrm{RHE}}$, similarly to Huang et al., ${ }^{10}$ and the number of cycles was further halved to last roughly the same amount of time as the other protocol. This upper potential extends the potential range considerably where $\mathrm{Pt}$ oxidation and the place exchange process between $\mathrm{Pt}$ and $\mathrm{O}$ atoms occur. ${ }^{40}$ The WAXS patterns are shown and compared in Figure $4 \mathrm{~b}$ after background (Figure S16) subtraction for the activated state and after both stability tests. No changes are observed for the L-stability test, while a shift to lower q values and a decrease in intensity occur for both catalysts subjected to the H-stability test.

A detailed analysis was conducted by Rietveld refinement, ${ }^{41}$ a method that takes into account the entire pattern and is more appropriate to discuss crystallite sizes and presence of multiple phases. It was found that a two fcc phase model fits better the patterns for dry state, wet state, activated, and after the Lstability test, while a single phase was sufficient to obtain a good fit of the state after H-stability. The two fcc phases can be interpreted as a Pt-rich and a Ni-rich PtNi alloy phase, due to the different lattice parameter. The lattice parameters are reported in Figure 4c,d, the sizes of the coherently scattering domains in Figure S17, and phase compositions in weight percentage in Figure S18. The in situ WAXS measurements were compared with the dry state obtained by XRD and show a generally good agreement between the wet and dry state considering the different measurement conditions. In the following, we will focus on differences among measurements done in situ, which are obtained at the synchrotron in the same cell and with the catalysts on the same substrate. For both catalysts, no significant changes in lattice parameter $a$ of the two fcc phases are observed between wet, activated, and after L-stability. Similarly, for the crystallite sizes, which are reported as averaged values in Table 2.

Table 2. Sizes of the Coherently Scattering Domains Obtained from Rietveld Refinement of oh-PtNi/C and oh$\operatorname{PtNi}(\mathrm{Mo}) / \mathrm{C}$

\begin{tabular}{|c|c|c|c|}
\hline & \multicolumn{3}{|c|}{ average size of the coherently scattering domains $(\mathrm{nm})$} \\
\hline & Pt-richer phase ${ }^{a}$ & Ni-richer phase ${ }^{a}$ & Pt-rich single phase ${ }^{b}$ \\
\hline $\mathrm{PtNi} / \mathrm{C}$ & 3 & 5 & 4.5 \\
\hline $\mathrm{PtNi}(\mathrm{Mo}) / \mathrm{C}$ & 1.5 & 6 & 4 \\
\hline $\begin{array}{l}{ }^{a} \text { Averaged an } \\
\text { stability. }\end{array}$ & ig wet, activ & , and after & tability. ${ }^{b}$ After $\mathrm{H}-$ \\
\hline
\end{tabular}

The Ni-rich phase of $\mathrm{PtNi}(\mathrm{Mo}) / \mathrm{C}$ is more contracted, slightly larger, and in slightly less percentage respect to the one in $\mathrm{PtNi} / \mathrm{C}$. The two Pt-rich phases have similar lattice parameters, but the one of $\mathrm{PtNi}(\mathrm{Mo})$ has a smaller size and is present in slightly higher percentages than the one of $\mathrm{PtNi}$ / C. The considerably smaller size of the Pt-rich phase of $\mathrm{PtNi}(\mathrm{Mo}) / \mathrm{C}$ with respect to the average particle size of the small shape-undefined particles as observed in TEM suggests that univocal association of the Pt-rich phase from Rietveld refinement with these small particles is unlikely. Therefore, the Pt phases from Rietveld refinement are interpreted as domains, which are part of larger particles. For both catalysts, the size of the Ni-richer phase matches very well with the average sizes calculated counting all particles in TEM images, leaving open the possibility that this phase may represent domains in both octahedral and shape-undefined nanoparticles.

In contrast to the discussed dual phase composition, a single phase is observed after the H-stability test, which is characterized by a similar lattice parameter as the Pt-rich phase, but crystallite sizes in between the two phases. The transformations to this phase were studied in detailed by Rietveld refinement (Figures S19 and 20). For PtNi/C (Figure $\mathrm{S} 19 \mathrm{a}$ ), the most significant changes are associated with the Nirich phase. The lattice parameter of this phase expanded only slightly but its amount decreased substantially in favor of the Pt-rich phase (Figure S20a,e). At the end of the stability test, the Ni-rich phase basically disappeared and only a Pt-rich phase remained. For PtNi(Mo)/C (Figure S19b), the Ni-rich phase expanded until the lattice parameter became similar to the Pt-rich phase, but the percentage amounts of the two phases remain constant (Figure S20b,f). The two phases were indistinguishable at the end of the test and therefore can be considered a single phase. Despite the slightly different behavior, the results for both catalysts might be similarly explained by a structural transformation, in which $\mathrm{Ni}$ atoms leave the Ni-richer alloy phase and the element distribution changes. To verify this hypothesis, $\mathrm{Ni}$ atomic content was measured by XRF and the metal percentage is shown in Figure 4e (note that Mo was beyond the XRF detection limit for all samples, so the percentage is referred only to $\mathrm{Pt}$ and $\mathrm{Ni}$ ). Interestingly, $\mathrm{PtNi}(\mathrm{Mo}) / \mathrm{C}$ maintains a higher $\mathrm{Ni}$ content in all the measurements with respect to $\mathrm{PtNi} / \mathrm{C}$. The higher $\mathrm{Ni}$ content of $\mathrm{PtNi}(\mathrm{Mo}) / \mathrm{C}$ with respect to $\mathrm{PtNi} / \mathrm{C}$ is qualitatively in agreement with the smaller lattice parameter as measured with in situ WAXS, but Vegard's Law is not satisfied. We notice that this is often the case for highly inhomogeneous materials, and in our case, the element anisotropy could easily explain the mismatch in the values observed in XRF. In addition, XRF is sensitive to all chemical states of $\mathrm{Ni}$, so including $\mathrm{Ni}$ atoms not necessarily in the metal state and "trapped" in the Nafion ionomer. Therefore, it is also possible that XRF overestimates the $\mathrm{Ni}$ content of the nanoparticles in part for this reason.

After activation, a decrease in $\mathrm{Ni}$ percentage content is observed for both catalysts. The percentage loss is roughly double for $\mathrm{PtNi} / \mathrm{C}$ than $\mathrm{PtNi}(\mathrm{Mo}) / \mathrm{C}$. However, no significant change in the lattice parameter $a$ is observed for $\mathrm{PtNi} / \mathrm{C}$ and similarly, within experimental error, for $\mathrm{PtNi}(\mathrm{Mo}) / \mathrm{C}$ (Figure 4). Therefore, we attribute this Ni loss mainly to dissolution of $\mathrm{Ni}$ from amorphous $\mathrm{NiO}_{x} \mathrm{H}_{y}$ at the surface. The presence of this phase at the surface is expected after the catalyst is exposed to air following the synthesis, ${ }^{42}$ due to high oxophilicity of $\mathrm{Ni}$. Leaching of $\mathrm{Ni}$ from the alloy phase can still happen in a minor amount, as suggested from small differences in $\mathrm{PtNi}(\mathrm{Mo}) / \mathrm{C}$. After the L-stability protocol, only a minor decrease in the fraction of $\mathrm{Ni}$ content is observed for $\mathrm{PtNi} / \mathrm{C}$, while for $\mathrm{PtNi}(\mathrm{Mo}) / \mathrm{C}$, it is roughly the same. This shows that if the upper potential is controlled and limited to or below 0.925 $\mathrm{V}_{\mathrm{RHE}}$, Ni leaching is slow for these catalysts and a higher number of cycles might be necessary to detect it. In contrast, after $\mathrm{H}$-stability, Ni content decreases for both. The percentage loss with respect to the activated state is roughly double for $\mathrm{PtNi} / \mathrm{C}$ than $\mathrm{PtNi}(\mathrm{Mo}) / \mathrm{C}$. SEM-EDX was performed as comparative verification of the low value of $\mathrm{Ni}$ content for $\mathrm{PtNi} / \mathrm{C}$ and confirmed XRF values (averaged Ni content of 14 
at. \% compared to 13 at. \% of XRF, Figure S21). The presence of $\mathrm{Mo}$ and/or the prolonged synthesis time for $\mathrm{PtNi}(\mathrm{Mo})$ helps to retain $\mathrm{Ni}$. Comparison of the initial activity among oh$\mathrm{PtNi}(\mathrm{Mo}) / \mathrm{C}$, oh-PtNi/C, and oh-PtNi/C-, two steps suggested that the extended synthesis time is not enough to justify the activity enhancement. Combining these observations, we suggest that the higher activity of $\mathrm{PtNi}(\mathrm{Mo}) / \mathrm{C}$ with respect to $\mathrm{PtNi} / \mathrm{C}$ is due to the higher $\mathrm{Ni}$ content that is retained thanks to a certain effect induced by the presence of Mo. STEM-EDX elemental maps of oh-PtNi(Mo)/C samples after the H-stability protocol confirm a reduced but still substantial presence of Ni (Figures S22 and S23). Despite the fact that the composition of single nanoparticles varies from 15 to $30 \mathrm{Ni}$ at. \%, the average over five different maps provides the value of $21 \pm 6 \mathrm{Ni}$ at. \%, which is well in agreement with the value for XRF, $22 \pm 1 \mathrm{Ni}$ at. \%. Similarly, the Ni composition found by XRF was confirmed by STEM-EDX elemental maps for oh-PtNi/C, $\sim 11 \pm 1 \mathrm{Ni}$ at. \% after averaging over a couple of overview maps (Figure S24). In addition, HAADF STEM images show a complete loss of shape for oh-PtNi/C (Figures S24a,c and S25), while some octahedral nanoparticles were still present for oh-PtNi(Mo)/C (Figure S23b). The significant Ni content found after $\mathrm{H}$-stability tests is surprising considering that the lattice parameters are in both cases close to the one of bulk Pt. As discussed before, this might be due to inhomogeneities in the materials and limitations of WAXS, which cannot access amorphous Ni-rich domains, which are probed by STEM-EDX or XRF.

In order to validate that the high potential of oh- $\mathrm{PtNi}(\mathrm{Mo}) /$ $\mathrm{C}$ shown in $\mathrm{RDE}$ experiments is maintained when the catalyst is part of a membrane electrode assembly (MEA), its performance was evaluated in a single-cell fuel cell setup. For the MEA measurements, $\sim 1 \mathrm{~g}$ of catalysts was synthesized (Figure S26). Catalyst-coated membranes were fabricated with an active area of $50 \mathrm{~cm}^{2}$. Figure 5a shows the performance obtained under $\mathrm{H}_{2} / \mathrm{O}_{2}$ (stoic $1.5 / 10$ ), $100 \%$ relative humidity, $80{ }^{\circ} \mathrm{C}$, and $50 \mathrm{kPa}_{\mathrm{g}}$ inlet pressure. In this condition, $\mathrm{O}_{2}$ related transport losses in the catalyst layer and at the Pt surface are minimized and it should be possible to reasonably assess the intrinsic activity of the catalyst.

$\mathrm{Oh}-\mathrm{PtNi}(\mathrm{Mo}) / \mathrm{C}$ showed an ORR mass activity at $0.9 \mathrm{~V}$ of $0.45 \mathrm{~A} \mathrm{mg}_{\mathrm{Pt}}{ }^{-1}$. For comparison, $\mathrm{Pt} / \mathrm{C}$ and $\mathrm{d}-\mathrm{PtNi} / \mathrm{C}$ showed a MA of 0.28 and $0.57 \mathrm{~A} \mathrm{mg}_{\mathrm{Pt}}{ }^{-1}$, respectively (additional comparisons are shown in Figure S27). The reason for the discrepancy that is often observed between the MA evaluated in MEA and RDE experiments, is a matter of discussion and might be due to different experimental conditions, i.e., temperature but also conditioning treatments, as well as catalyst layer quality. ${ }^{13,14}$ Despite the fact that the performance obtained in the single cell is much less than in RDE, we note that it is among the best reported in the literature for shaped Pt-alloy nanostructured catalysts tested in MEA ${ }^{15,18,19}$ and comes just shortly after the state-of-the-art performance that was obtained with dealloyed catalysts. ${ }^{15,43,44}$ This latter is well reproduced by the $\mathrm{d}-\mathrm{PtNi} / \mathrm{C}$ tested in this work. The performance in $\mathrm{H}_{2}$ /air (stoic $1.5 / 2$ ) is reported in Figure 5 b. In this condition, a lower current density is measured for the oh- $\mathrm{PtNi}(\mathrm{Mo}) / \mathrm{C}$ (loading: $0.1 \mathrm{mg}_{\mathrm{Pt}} \mathrm{cm}^{-2}$ ) with respect to the $\mathrm{Pt} / \mathrm{C}\left(0.2 \mathrm{mg}_{\mathrm{Pt}} \mathrm{cm}^{-2}\right)$ and $\mathrm{d}-\mathrm{PtNi} / \mathrm{C}\left(0.1 \mathrm{mg}_{\mathrm{Pt}} \mathrm{cm}^{-2}\right)$. This trend in current densities might be due to the lower ECSA of the oh- $\mathrm{PtNi}(\mathrm{Mo}) / \mathrm{C}$ with respect to the other two catalysts. The low ECSA was confirmed by a CO stripping method using the cell in half-cell mode, where the anode electrode acts as a a)

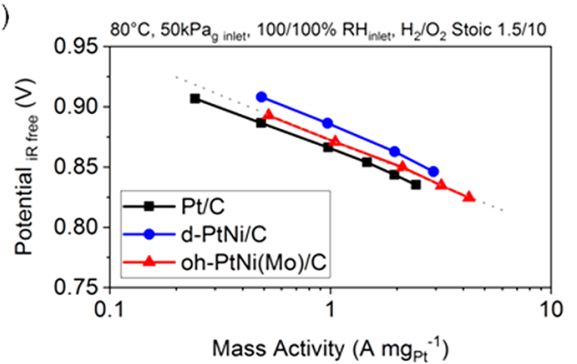

b)

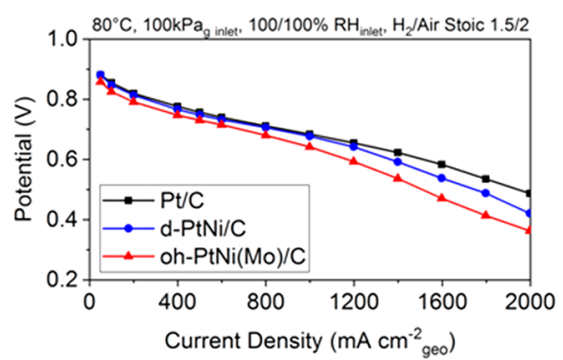

Figure 5. MEA single-cell performance with oh- $\mathrm{PtNi}(\mathrm{Mo}) / \mathrm{C}$ (red), $\mathrm{d}-\mathrm{PtNi} / \mathrm{C}$ (blue), and $\mathrm{Pt} / \mathrm{C}$ (black) as the cathode and $\mathrm{Pt} / \mathrm{C}$ as the anode in $\mathrm{H}_{2} / \mathrm{O}_{2}$ (a) and $\mathrm{H}_{2} /$ air (b). Polarization curves as a function of mass activity and current density are shown in panels $a$ and $b$, respectively. The cathode loading was $0.2 \mathrm{mg}_{\mathrm{Pt}} \mathrm{cm}^{-2}$ for the $\mathrm{Pt} / \mathrm{C}$ and $0.1 \mathrm{mg}_{\mathrm{Pt}} \mathrm{cm}^{-2}$ for the other two catalysts. The loading for the anode was $0.1 \mathrm{mg}_{\mathrm{Pt}} \mathrm{cm}^{-2}$. Other experimental conditions are reported above the plots.

pseudo reference electrode. The ECSA, $26 \mathrm{~m}^{2} \mathrm{~g}_{\mathrm{Pt}}{ }^{-1}$, was less than half the ones of the other two catalysts $\left(58 \mathrm{~m}^{2} \mathrm{~g}_{\mathrm{Pt}}{ }^{-1}\right.$ for $\mathrm{Pt} / \mathrm{C}$ and $65 \mathrm{~m}^{2} \mathrm{~g}_{\mathrm{Pt}}{ }^{-1}$ for $\left.\mathrm{d}-\mathrm{PtNi} / \mathrm{C}\right)$. It has been shown that low ECSA leads to a detrimental performance at high current densities in low Pt loading cathodes due to local oxygen transport resistance at the Pt surface of the nanoparticles. ${ }^{13}$ Following this hypothesis, a narrower size distribution for the oh-PtNi(Mo)/C nanoparticles centered at lower sizes should increase the ECSA and might improve the $\mathrm{H}_{2}$ /air performance. Comparison of $\mathrm{H}_{2}$ /air performance within data in the literature for shaped $\mathrm{Pt}$ alloy nanoparticles is more difficult than for $\mathrm{H}_{2} / \mathrm{O}_{2}$, due to the more diverse conditions and in general to the less data availability. ${ }^{16-18}$ The current density of $1170 \mathrm{~mA} \mathrm{~cm}^{-2}$ geo at $0.6 \mathrm{~V}$ was measured for oh- $\mathrm{PtNi}(\mathrm{Mo}) / \mathrm{C}$, corresponding to the power density of $0.70 \mathrm{~W} / \mathrm{cm}^{2}$ and a $\mathrm{Pt}$ utilization values of $0.28 \mathrm{~g}_{\mathrm{Pt}} / \mathrm{kW}$. Also in this case, the performance of the $\mathrm{d}-\mathrm{PtNi} / \mathrm{C}, 1370 \mathrm{~mA} \mathrm{~cm}{ }_{\text {geo }}^{-2}$ at $0.6 \mathrm{~V}$, is close to the one of the state-of-the-art dealloyed $\mathrm{PtNi} / \mathrm{C}$ catalysts. $^{44}$ Summarizing these results, the single-cell activity performances of the fabricated MEA are comparable with the state-of-the-art dealloyed catalysts and among the best ones for shaped Pt alloy catalysts. This shows that the oh-PtNi(Mo)/C catalyst synthesized in this work is a promising catalyst for the cathode of fuel cells.

In conclusion, we show the translation of the exceptionally high ORR activity of octahedral $\mathrm{PtNi}(\mathrm{Mo})$ nanoparticles from conventional thin-film RDE screenings $\left(3.43 \pm 0.35 \mathrm{~A} \mathrm{mg}_{\mathrm{Pt}}{ }^{-1}\right.$ at $0.9 \mathrm{~V}_{\mathrm{RHE}}$ ) to MEA-based single fuel cell tests with sustained Pt mass activities of $0.45 \mathrm{~A} \mathrm{mg}_{\mathrm{Pt}}{ }^{-1}$ at $0.9 \mathrm{~V}_{\text {cell }}$ one of the highest ever reported performances for shaped $\mathrm{Pt}$ alloys nanocatalysts. STEM-EDX elemental mapping showed that $\mathrm{Mo}$ atoms in octahedral surface-doped $\mathrm{PtNi} / \mathrm{C}$ nanoparticles with an anisotropic element distribution are preferentially located at the Pt-rich edges and vertices. The high mass activity 
of this catalyst and the slightly better stability with respect to undoped octahedral $\mathrm{PtNi} / \mathrm{C}$ were related to the enhancement in $\mathrm{Ni}$ retention in the $\mathrm{PtNi}$ alloy phase due to the presence of Mo. This was achieved by a combination of in situ WAXS, XRF, and STEM-EDX elemental maps with electrochemical measurements. The loss in activity after stability tests with a controlled cycling upper potential that was limited to 0.925 $\mathrm{V}_{\mathrm{RHE}}$ is proposed to be mainly due to morphological instability. In this condition, $\mathrm{Ni}$ loss and structural transformations were limited and slow when the number of cycles was kept equal to 5000. However, for a potential up to $1.26 \mathrm{~V}_{\mathrm{RHE}}$ major crystal structure transformations occur simultaneously to Ni leaching, even with 2500 cycles. The atomic level insights about the surface preferential location of Mo will help in the design of new surface-doped shape-selected catalysts for the ORR reaction. In addition, the impact of Mo adatoms on the $\mathrm{Ni}$ surface composition, which in turn is responsible for the high ORR activity, calls for strategy on how to preserve that particular near-surface $\mathrm{Ni}$ composition to increase the stability of shape-controlled Pt-based alloy catalysts for fuel cell cathodes.

\section{ASSOCIATED CONTENT}

\section{S Supporting Information}

The Supporting Information is available free of charge on the ACS Publications website at DOI: 10.1021/acs.nanolett.9b02116.

Experimental details, discussion about the results of the CO stripping study, TEM images, HAADF-STEM images and EDX compositions maps, cyclic voltammetry and linear sweep voltammetry, and $\mathrm{CO}$ stripping voltammetry, comparison of CO-ECSA and $\mathrm{H}_{\text {upd }}{ }^{-}$ ECSA, bar plot of the first moment of the potential weight, photography of the in situ WAXS setup, example of WAXS pattern, crystallite sizes and phase compositions from Rietveld refinement, and SEM images (PDF)

\section{AUTHOR INFORMATION}

\section{Corresponding Author}

*E-mail: pstrasser@tu-berlin.de.

\section{ORCID $\odot$}

P. Strasser: 0000-0002-3884-436X

\section{Author Contributions}

The manuscript was written through contributions of all authors. All authors have given approval to the final version of the manuscript.

\section{Notes}

The authors declare no competing financial interest.

\section{ACKNOWLEDGMENTS}

The project leading to this application has received funding from the Fuel Cells and Hydrogen 2 Joint Undertaking under grant agreement no. 700127. This Joint Undertaking receives support from the European Union's Horizon 2020 research and Innovation Programme and Hydrogen Europe and N.ERGHY. We acknowledge Annette Wittebrock for her help in the laboratory, Thomas Merzdorf for the help at the beamline, and Johnson Matthey Fuel Cells Ltd for the supply of catalysts and helpful discussions. Financial support of the Deutsche Forschungsgemeinschaft (DFG) grant STR 596/5-1, 596/5-2 and HE 7192/1-1, 7192/1-2 is gratefully acknowl- edged. The authors would also like to thank the ESRF ID31 beamline staff for help during the beamtime.

\section{REFERENCES}

(1) Kim, C.; Dionigi, F.; Beermann, V.; Wang, X.; Möller, T.; Strasser, P. Adv. Mater. 2019, 31, 1805617.

(2) Bu, L. Z.; Zhang, N.; Guo, S. J.; Zhang, X.; Li, J.; Yao, J. L.; Wu, T.; Lu, G.; Ma, J. Y.; Su, D.; Huang, X. Q. Science 2016, 354 (6318), $1410-1414$.

(3) Cui, C. H.; Gan, L.; Heggen, M.; Rudi, S.; Strasser, P. Nat. Mater. 2013, 12 (8), 765-771.

(4) Escudero-Escribano, M.; Malacrida, P.; Hansen, M. H.; VejHansen, U. G.; Velazquez-Palenzuela, A.; Tripkovic, V.; Schiotz, J.; Rossmeisl, J.; Stephens, I. E. L.; Chorkendorff, I. Science 2016, 352 (6281), 73-76.

(5) Greeley, J.; Stephens, I. E. L.; Bondarenko, A. S.; Johansson, T. P.; Hansen, H. A.; Jaramillo, T. F.; Rossmeisl, J.; Chorkendorff, I.; Norskov, J. K. Nat. Chem. 2009, 1 (7), 552-556.

(6) Park, J.; Zhang, L.; Choi, S. I.; Roling, L. T.; Lu, N.; Herron, J. A.; Xie, S. F.; Wang, J. G.; Kim, M. J.; Mavrikakis, M.; Xia, Y. N. ACS Nano 2015, 9 (3), 2635-2647.

(7) Stamenkovic, V. R.; Mun, B. S.; Arenz, M.; Mayrhofer, K. J. J.; Lucas, C. A.; Wang, G. F.; Ross, P. N.; Markovic, N. M. Nat. Mater. 2007, 6 (3), 241-247.

(8) Strasser, P.; Koh, S.; Anniyev, T.; Greeley, J.; More, K.; Yu, C. F.; Liu, Z. C.; Kaya, S.; Nordlund, D.; Ogasawara, H.; Toney, M. F.; Nilsson, A. Nat. Chem. 2010, 2 (6), 454-460.

(9) Choi, S. I.; Xie, S. F.; Shao, M. H.; Odell, J. H.; Lu, N.; Peng, H. C.; Protsailo, L.; Guerrero, S.; Park, J. H.; Xia, X. H.; Wang, J. G.; Kim, M. J.; Xia, Y. N. Nano Lett. 2013, 13 (7), 3420-3425.

(10) Huang, X. Q.; Zhao, Z. P.; Cao, L.; Chen, Y.; Zhu, E. B.; Lin, Z. Y.; Li, M. F.; Yan, A. M.; Zettl, A.; Wang, Y. M.; Duan, X. F.; Mueller, T.; Huang, Y. Science 2015, 348 (6240), 1230-1234.

(11) Strasser, P. Science 2015, 349 (6246), 379-380.

(12) García-Cruz, L.; Montiel, V.; Solla-Gullón, J. Phys. Sci. Rev. 2019, 4 (1), 34.

(13) Kongkanand, A.; Mathias, M. F. J. Phys. Chem. Lett. 2016, 7 (7), 1127-1137.

(14) Stephens, I. E. L.; Rossmeisl, J.; Chorkendorff, I. Science 2016, 354 (6318), 1378-1379.

(15) Garrick, T. R.; Moylan, T. E.; Carpenter, M. K.; Kongkanand, A. J. Electrochem. Soc. 2017, 164 (2), F55-F59.

(16) Lim, J.; Shin, H.; Kim, M.; Lee, H.; Lee, K. S.; Kwon, Y.; Song, D.; Oh, S.; Kim, H.; Cho, E. Nano Lett. 2018, 18 (4), 2450-2458.

(17) Wang, J.; Li, B.; Yang, D. J.; Lv, H.; Zhang, C. M. RSC Adv. 2018, 8 (33), 18381-18387.

(18) Mauger, S. A.; Neyerlin, K. C.; Alia, S. M.; Ngo, C.; Babu, S. K.; Hurst, K. E.; Pylypenko, S.; Litster, S.; Pivovar, B. S. J. Electrochem. Soc. 2018, 165 (3), F238-F245.

(19) Peng, X.; Zhao, S.; Omasta, T. J.; Roller, J. M.; Mustain, W. E. Appl. Catal., B 2017, 203, 927-935.

(20) Gan, L.; Cui, C. H.; Heggen, M.; Dionigi, F.; Rudi, S.; Strasser, P. Science 2014, 346 (6216), 1502-1506.

(21) Aran-Ais, R. M.; Dionigi, F.; Merzdorf, T.; Gocyla, M.; Heggen, M.; Dunin-Borkowski, R. E.; Gliech, M.; Solla-Gullon, J.; Herrero, E.; Feliu, J. M.; Strasser, P. Nano Lett. 2015, 15 (11), 7473-7480.

(22) Huang, X. Q.; Zhao, Z. P.; Chen, Y.; Zhu, E. B.; Li, M. F.; Duan, X. F.; Huang, Y. Energy Environ. Sci. 2014, 7 (9), 2957-2962.

(23) Zhao, Z. P.; Feng, M.; Zhou, J. H.; Liu, Z. Y.; Li, M. F.; Fan, Z.; Tsen, O.; Miao, J. W.; Duan, X. F.; Huang, Y. Chem. Commun. 2016, 52 (75), 11215-11218.

(24) Zhang, C. L.; Sandorf, W.; Peng, Z. M. ACS Catal. 2015, 5 (4), 2296-2300.

(25) Antolini, E. Int. J. Energy Res. 2018, 42 (12), 3747-3769.

(26) Beermann, V.; Gocyla, M.; Willinger, E.; Rudi, S.; Heggen, M.; Dunin-Borkowski, R. E.; Willinger, M. G.; Strasser, P. Nano Lett. 2016, 16 (3), 1719-1725.

(27) Cao, L.; Mueller, T. Nano Lett. 2016, 16 (12), 7748-7754. 
(28) Jia, Q. Y.; Zhao, Z. P.; Cao, L.; Li, J. K.; Ghoshal, S.; Davies, V.; Stavitski, E.; Attenkofer, K.; Liu, Z. Y.; Li, M. F.; Duan, X. F.; Mukerjee, S.; Mueller, T.; Huang, Y. Nano Lett. 2018, 18 (2), 798804.

(29) Luo, Y.; Kirchhoff, B.; Fantauzzi, D.; Calvillo, L.; EstudilloWong, L. A.; Granozzi, G.; Jacob, T.; Alonso-Vante, N. ChemSusChem 2018, 11 (1), 193-201.

(30) Cho, K. Y.; Yeom, Y. S.; Seo, H. Y.; Kumar, P.; Lee, A. S.; Baek, K. Y.; Yoon, H. G. ACS Appl. Mater. Interfaces 2017, 9 (2), 15241535.

(31) Mao, J. J.; Chen, W. X.; He, D. S.; Wan, J. W.; Pei, J. J.; Dong, J. C.; Wang, Y.; An, P. F.; Jin, Z.; Xing, W.; Tang, H. L.; Zhuang, Z. B.; Liang, X.; Huang, Y.; Zhou, G.; Wang, L. Y.; Wang, D. S.; Li, Y. D. Sci. Adv. 2017, 3 (8), e1603068.

(32) Kuhl, S.; Heyen, H.; Strasser, P. ECS Trans. 2016, 75 (14), 723-730.

(33) Martens, S.; Asen, L.; Ercolano, G.; Dionigi, F.; Zalitis, C.; Hawkins, A.; Bonastre, A. M.; Seidl, L.; Knoll, A. C.; Sharman, J.; Strasser, P.; Jones, D.; Schneider, O. J. Power Sources 2018, 392, 274284.

(34) Stamenkovic, V. R.; Fowler, B.; Mun, B. S.; Wang, G. F.; Ross, P. N.; Lucas, C. A.; Markovic, N. M. Science 2007, 315 (5811), 493497.

(35) Nikolaychuk, P. A.; Tyurin, A. G. Butlerov Communications 2011, 24 (2), 101-105.

(36) Elezovic, N. R.; Babic, B. M.; Radmilovic, V. R.; Gojkovic, S. L.; Krstajic, N. V.; Vracar, L. M. J. Power Sources 2008, 175 (1), 250255.

(37) Borgschulte, A.; Sambalova, O.; Delmelle, R.; Jenatsch, S.; Hany, R.; Nuesch, F. Sci. Rep. 2017, 7, 7.

(38) Chen, C.; Kang, Y. J.; Huo, Z. Y.; Zhu, Z. W.; Huang, W. Y.; Xin, H. L. L.; Snyder, J. D.; Li, D. G.; Herron, J. A.; Mavrikakis, M.; Chi, M. F.; More, K. L.; Li, Y. D.; Markovic, N. M.; Somorjai, G. A.; Yang, P. D.; Stamenkovic, V. R. Science 2014, 343 (6177), 13391343.

(39) Luo, M. C.; Guo, S. J. Nat. Rev. Mater. 2017, 2 (11), 1.

(40) Drnec, J.; Ruge, M.; Reikowski, F.; Rahn, B.; Carla, F.; Felici, R.; Stettner, J.; Magnussen, O. M.; Harrington, D. A. Electrochim. Acta 2017, 224, 220-227.

(41) Rietveld, H. M. J. Appl. Crystallogr. 1969, 2, 65-71.

(42) Cui, C.; Ahmadi, M.; Behafarid, F.; Gan, L.; Neumann, M.; Heggen, M.; Roldan Cuenya, B.; Strasser, P. Faraday Discuss. 2013, $162,91-112$.

(43) Yarlagadda, V.; Carpenter, M. K.; Moylan, T. E.; Kukreja, R. S.; Koestner, R.; Gu, W. B.; Thompson, L.; Kongkanand, A. Acs Energy Letters 2018, 3 (3), 618-621.

(44) Han, B. H.; Carlton, C. E.; Kongkanand, A.; Kukreja, R. S.; Theobald, B. R.; Gan, L.; O’Malley, R.; Strasser, P.; Wagner, F. T.; Shao-Horn, Y. Energy Environ. Sci. 2015, 8 (1), 258-266. 